Regular article

\title{
Microbial production of hyaluronic acid from agro-industrial by-products: Molasses and corn steep liquor
}

\author{
Isabel R. Amado ${ }^{\mathrm{a}, \mathrm{d}, *}$, José A. Vázquez ${ }^{\mathrm{b}}$, Lorenzo Pastrana ${ }^{\mathrm{c}}$, José A. Teixeira ${ }^{\mathrm{d}}$ \\ a Departamento de Química Analítica y Alimentaria, Universidad de Vigo, Ourense, Spain \\ b Grupo de Reciclado y Valorización de Materiales Residuales (REVAL), IIM-CSIC, Vigo, Spain \\ c International Iberian Nanotechnology Laboratory (INL), Avda. Mestre José Veiga s/n, 4715 Braga, Portugal \\ ${ }^{d}$ CEB - Centre of Biological Engineering, University of Minho, 4710-057 Braga, Portugal
}

\section{A R T I C L E I N F O}

\section{Article history:}

Received 6 May 2016

Received in revised form

22 September 2016

Accepted 26 September 2016

Available online 15 October 2016

\section{Keywords:}

Food waste

Hyaluronic acid

Polysaccharide

Submerged culture

Streptococcus zooepidemicus

Biorefinery

\begin{abstract}
A B S T R A C T
Agro-industrial by-products are being explored as alternative low-cost nutrients to produce hyaluronic acid (HA) by Streptococcus zooepidemicus. In this study, we formulated three culture media containing corn steep liquor (CSL) and sugarcane molasses (M), to produce microbial HA using batch bioreactor conditions ( $\mathrm{pH} 6.7,500 \mathrm{rpm}$ and $1 \mathrm{vvm}$ aeration). Final HA concentrations of $3.48 \mathrm{~g} \mathrm{~L}^{-1}$ were produced in culture medium containing corn steep liquor $(10 \% \mathrm{v} / \mathrm{v})$ and glucose, being comparable $\left(3.60 \mathrm{~g} \mathrm{~L}^{-1}\right)$ to the control medium containing tryptone and glucose. The use of molasses $(10 \% \mathrm{v} / \mathrm{v})$ as carbon source produced a marked inhibition of $S$. zooepidemicus growth and HA production due to a low sugar consumption. The HA produced in CSL culture media had a high molecular weight of $3.8 \times 10^{3} \mathrm{kDa}$, greater than HA produced in tryptone-containing medium $\left(3.0 \times 10^{3} \mathrm{kDa}\right)$.

This is the first report achieving HA productions comparable to synthetic a medium in a batch bioreactor using CSL as the main nitrogen source. However, further optimization of culture conditions must be carried out towards using this agricultural by-product for the sustainable industrial production of HA.
\end{abstract}

(C) 2016 Elsevier B.V. All rights reserved.

\section{Introduction}

Hyaluronic acid (HA) is a glycosaminoglycan found in vertebrate tissues as an essential component of the extracellular matrix. This polysaccharide has a linear structure consisting of $\beta-1,3-N-$

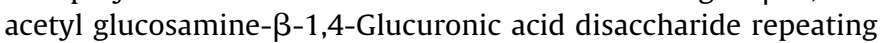
units [1]. Despite the simplicity of its structure, the polymer is semi-flexible and adopts an expanded wormlike random coil conformation in solution [2], exhibiting an unusual rheological behaviour. HA is an attractive molecule for specific applications in the cosmetic [3], pharmacological [4] and medical sectors [5] due to its viscoelasticity together with other advantages such as biocompatibility, angiogenic and immunostimulatory properties.

HA was traditionally recovered from rooster combs, synovial fluid, vitreous humour and umbilical cords [6] from terrestrial animals, but also from marine supplies [7]. In recent years, the microbial production by Streptococci was extensively investigated [8] due to improved HA yields, more efficient downstream pro-

\footnotetext{
* Corresponding author at: Departamento de Química Analítica y Alimentaria, Universidad de Vigo, Ourense, Spain.

E-mail address: sabelara@uvigo.es (I.R. Amado).
}

cesses, and reduced risk of cross-species viral infection [9]. In spite of these advantages, microbial cultivation must be cost competitive with HA recovery from animal sources. Streptococci have complex nutrient requirements on organic nitrogen [10], and nutritive media commonly used to grow these microorganisms contain high amounts of rich nutrients [11]. The continuous increment in the cost of these raw materials reduces the commercial competitiveness of microbial HA production [8] and therefore, the use of low-cost renewable resources and agro-industrial by-products as culture media contributes towards making HA production economically feasible.

Molasses is a by-product of the sugar cane industry containing valuable compounds for the fermentation process like sucrose, minerals, organic compounds and vitamins [12]. CSL is a by-product of the corn wet milling industry rich in vitamins, minerals, amino acids and proteins, and an important source of nitrogen [13]. The high nutritive value of both substrates suggests they could be useful for the formulation of culture medium to produce HA using a bacterium with complex nutrient requirements like $S$. zooepidemicus.

The production of HA using renewable resources as ingredients for the formulation of culture media is being explored nowadays [14]. The substitution of commercial peptones by marine 
by-products [15-17], and cheese-whey protein [18] yielded high concentrations of HA in batch cultures of Streptococcus zooepidemicus. Vegetable by-products are also extensively explored because HA for cosmetic and pharmacological applications must be produced from non-animal sources [19]. De Macedo and Santana [20] found juice-moisturized bagasse with cashew apple fruit was a promising $(>6 \mathrm{mg} / \mathrm{g})$ source for the production of low molecular weight HA $\left(10^{4}-10^{5} \mathrm{Da}\right)$ in solid-state fermentation. In another study, HA was produced in culture medium containing corn steep liquor (CSL, $0.86 \mathrm{~g} \mathrm{~L}^{-1}$ ), or soy protein hydrolysate alone and combined with CSL $\left(0.17 \mathrm{~g} \mathrm{~L}^{-1}\right)$ as nitrogen sources [21]. Pan et al. [22] reported the replacement of yeast extract by soy protein resulted in a polymer production of $0.22 \mathrm{~g} \mathrm{~L}^{-1}$ while these authors did not find any HA production using CSL as the nitrogen source.

The objective of this work is the development of a low-cost alternative medium for the production of HA by S. zooepidemicus using molasses and corn steep liquor. The appropriate conditions ( $\mathrm{pH}$ control, agitation, and aeration) for the production of HA were first defined in culture medium containing glucose and tryptone, and performances compared to alternative culture media.

\section{Material and methods}

\subsection{Strain and culture conditions}

The HA-producing strain Streptococcus equi subsp. zooepidemicus ATCC 35246 was stored at $-80^{\circ} \mathrm{C}$ in complex medium (CM) with $25 \%$ glycerol. The composition of $\mathrm{CM}$ medium was $\left(\mathrm{g} \mathrm{L}^{-1}\right)$ : glucose 50.0; tryptone 15.0; yeast extract 2.75; $\mathrm{KH}_{2} \mathrm{PO}_{4} 2.00 ; \mathrm{K}_{2} \mathrm{HPO}_{4} 2.0$; $\mathrm{MgSO}_{4} 2.0 ;\left(\mathrm{NH}_{4}\right)_{2} \mathrm{SO}_{4} 0.5 ; \mathrm{pH}$ 6.7. The inoculum consisted of a $10 \%$ $(\mathrm{v} / \mathrm{v})$ as reported by Armstrong et al. [10], and detailed in Vázquez et al. [15].

Cultures were carried out in $0.75 \mathrm{~L}$-bioreactor with a working volume of $0.5 \mathrm{~L}$ (Biostat Q, Braun Sartorius), at $37^{\circ} \mathrm{C}$. We tested different agitation (200, 500 and $800 \mathrm{rpm})$ and aeration $(0,1 \mathrm{vvm})$ conditions in $\mathrm{CM}$ medium, and the $\mathrm{pH}$ maintained at 6.7 using $5 \mathrm{M}$ $\mathrm{NaOH}$.

\subsection{Streptococcus zooepidemicus culture using alternative substrates}

Sugarcane molasses, kindly provided by RAR: Refinarias de Açúcar Reunidas, S.A. (Portugal), and CSL kindly provided by COPAM: Companhia Portuguesa de Amidos, S.A. (Portugal) were the alternative substrates for HA production by Streptococcus zooepidemicus ATCC 35246. Molasses contained $495 \mathrm{~g} \mathrm{~L}^{-1}$ of carbohydrates and $20 \mathrm{gL}^{-1}$ of protein, while CSL contained $69 \mathrm{gL}^{-1}$ of carbohydrates, and $57 \mathrm{~g} \mathrm{~L}^{-1}$ of protein. Molasses (M) were dissolved in distilled water $(10 \%(\mathrm{v} / \mathrm{v}))$, and tested as culture media containing either tryptone or $10 \%(\mathrm{v} / \mathrm{v})$ corn steep liquor (CSLM). A third culture medium containing $50 \mathrm{~g} \mathrm{~L}^{-1}$ glucose, and $10 \%(\mathrm{v} / \mathrm{v})$ corn steep liquor was prepared (CSL). All media were supplemented with yeast extract, $\mathrm{KH}_{2} \mathrm{PO}_{4}, \mathrm{~K}_{2} \mathrm{HPO}_{4}, \mathrm{MgSO}_{4}$, and $\left(\mathrm{NH}_{4}\right)_{2} \mathrm{SO}_{4}$ at the same levels as $\mathrm{CM}$ medium (Table 1 ). The initial $\mathrm{pH}$ was adjusted to $\mathrm{pH} 6.7$ and the cultures carried out under previously defined conditions $\left(37^{\circ} \mathrm{C}, 500 \mathrm{rpm}, 1 \mathrm{vvm}\right)$.

\subsection{Analytical methods}

Samples were taken at different time points of fermentation and incubated with a $10 \%$ of $5 \%(w / v)$ SDS for $10 \mathrm{~min}$. Biomass was removed by centrifugation at $15000 \times g$ for $15 \mathrm{~min}$ and the optical density (OD) measured at $700 \mathrm{~nm}$. We quantified the concentration of total sugars and soluble proteins in the supernatant using the methods phenol-sulphuric [23] and Lowry [24], respectively.
Table 1

Composition of culture media $\left(\mathrm{g} \mathrm{L}^{-1}\right)$ utilised for the production of hyaluronic acid by Streptococcus zooepidemicus ATCC 35246. M: culture medium containing sugarcane molasses, CSL: culture medium containing corn steep liquor, CSLM: culture medium containing sugarcane molasses and corn steep liquor, CM: complex medium.

\begin{tabular}{lllll}
\hline & $\mathrm{M}$ & CSL & CSLM & CM \\
\hline Glucose & - & 50.00 & - & 50.00 \\
Yeast extract & 5.00 & 5.00 & 5.00 & 5.00 \\
Tryptone & 15.0 & - & - & 15.00 \\
$\mathrm{KH}_{2} \mathrm{PO}_{4}$ & 2.00 & 2.00 & 2.00 & 2.00 \\
$\mathrm{~K}_{2} \mathrm{HPO}_{4}$ & 0.50 & 0.50 & 0.50 & 0.50 \\
$\mathrm{MgSO}_{4}$ & 0.50 & 0.50 & 0.50 & 0.50 \\
$\left(\mathrm{NH}_{4}\right)_{2} \mathrm{SO}_{4}$ & 0.50 & 0.50 & 0.50 & 0.50 \\
Molasess $(\% \mathrm{v} / \mathrm{v})$ & 10.0 & - & 10.0 & - \\
CSL $(\% / \mathrm{v})$ & - & 10.0 & 10.0 & - \\
\hline
\end{tabular}

Glucose and sucrose were quantified by HPLC using an ION-300 column (Transgenomic, USA) with $6 \mathrm{mM}$ sulphuric acid as the mobile phase (flow $=0.4 \mathrm{~mL} / \mathrm{min}$ ) at $65^{\circ} \mathrm{C}$ and a refractive index detector.

The production of HA was quantified after selective precipitation in the supernatant using ethanol (3:1) followed by centrifugation $(10000 \times \mathrm{g}, 10 \mathrm{~min})$. The sediment was dissolved in $1.5 \mathrm{M} \mathrm{NaCl}(1: 1)$ and re-precipitated under the same conditions. Finally, the HA was suspended in distilled water and the concentration determined by the method of Blumenkrantz and Asboe-Hansen [25], following the modifications proposed by Murado et al. [26]. The molecular weight (MW) of HA was determined by size-exclusion chromatography with an Ultrahydrogel linear column (Waters, USA) with $0.1 \mathrm{M} \mathrm{NaNO}_{3}$ as the mobile phase (flow $=0.8 \mathrm{~mL} / \mathrm{min}$ ) and a refractive-index detector. Standards of polystyrene sulphonate (Sigma) with different molecular weights $(32,77,150,330,990$ and $2600 \mathrm{kDa})$ were used for calibration.

\subsection{Numerical and statistical analysis}

S. zooepidemicus growth $(X)$ kinetics were modelled using the following logistic equation [16]:

$X=\frac{X_{m}}{\left(1+\exp \left[2+\left(\frac{4 V_{X}}{X_{m}}\right)\left(\lambda_{X}-t\right)\right]\right)}$

where $X$ is the biomass production $\left(\mathrm{gL}^{-1}\right), X_{m}$ is the maximum biomass $\left(\mathrm{g} \mathrm{L}^{-1}\right), v_{x}$ is the maximum growth rate $\left(\mathrm{g} \mathrm{L}^{-1} \mathrm{~h}^{-1}\right)$ and $\lambda_{x}$ is the growth lag phase $(\mathrm{h})$.

Also a logistic equation was employed to model HA production data [16]:

$H=\frac{H_{m}}{\left(1+\exp \left[2+\left(\frac{4 v_{H}}{H_{m}}\right)\left(\lambda_{H}-t\right)\right]\right)}$

where $H$ is the HA production $\left(\mathrm{g} \mathrm{L}^{-1}\right), H_{m}$ is the maximum HA concentration $\left(\mathrm{g} \mathrm{L}^{-1}\right), v_{\mathrm{H}}$ is the maximum $\mathrm{HA}$ production rate $\left(\mathrm{g} \mathrm{L}^{-1} \mathrm{~h}^{-1}\right)$ and $\lambda_{H}$ is the delay in HA production $(\mathrm{h})$.

We calculated the yield of HA production on biomass by means of the following equation [27]:

$H=Y_{H / x} \frac{X_{m}}{1+\exp \left[2+\frac{4 v_{X}}{X_{m}}\left(\lambda_{X}-t\right)\right]}-Y_{H / x} X_{0}$

where $Y_{H / x}$ is the yield of HA production per biomass $\left(\mathrm{g} \mathrm{HAg}^{-1}\right.$ biomass).

Plotting and data fitting were performed using the software GraphPad PrismTM 5 (GraphPad Software Inc., San Diego, CA, USA). The significance of the mathematical models (Fisher's F-test) was assessed using the "SolverAid" macro (Levie's Excellaneous website: http://www.bowdoin.edu/ rdelevie/excellaneous). 

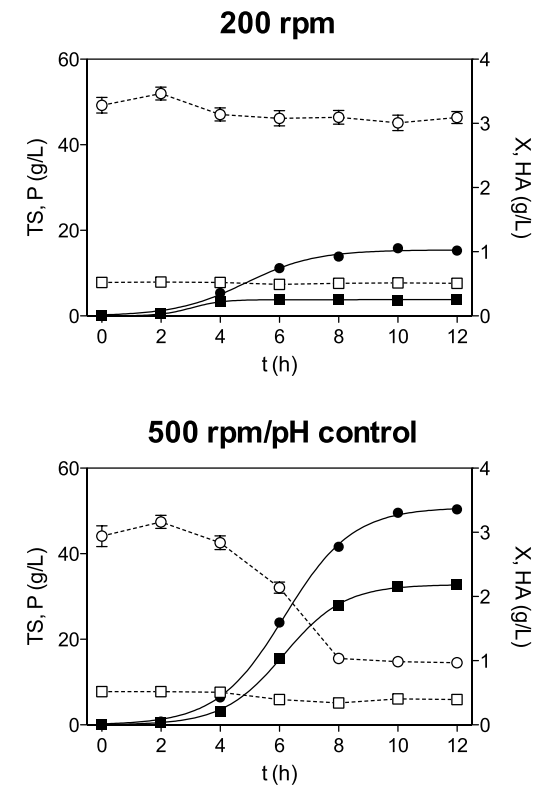

$800 \mathrm{rpm} / \mathrm{pH}$ control/1 vvm

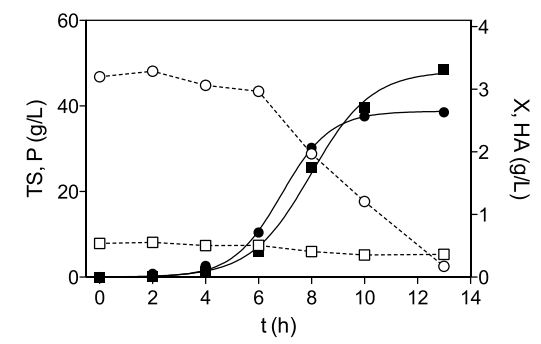

$500 \mathrm{rpm}$
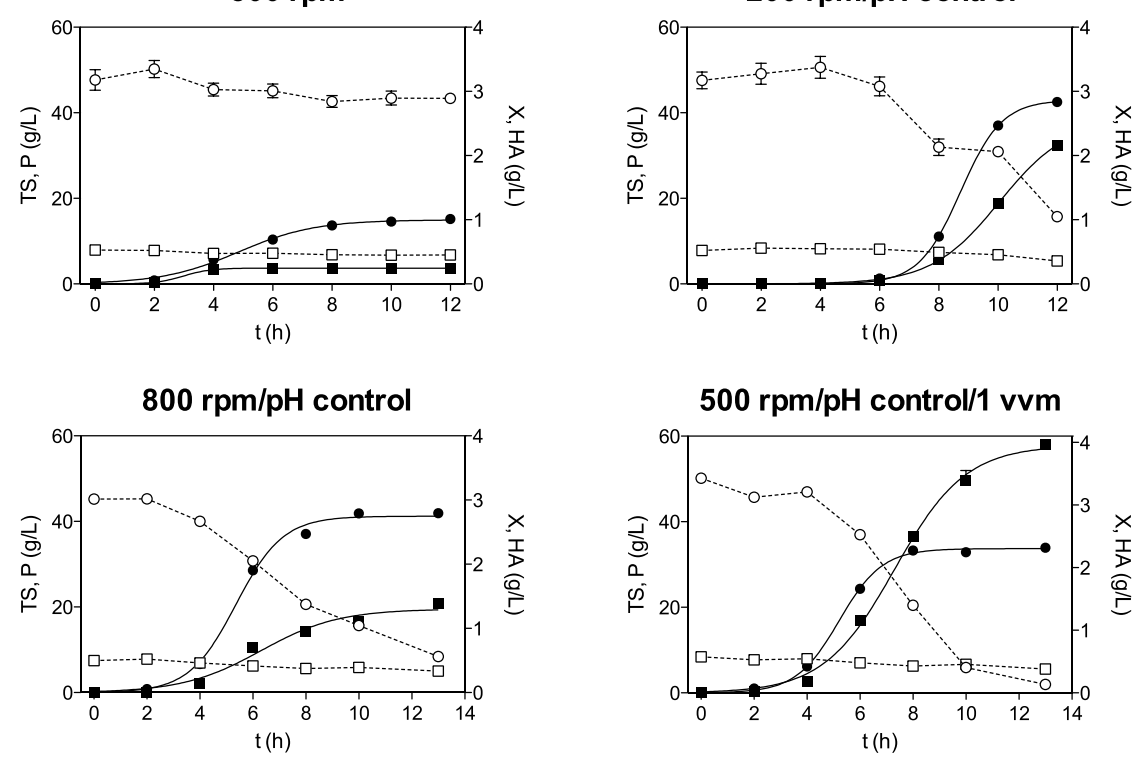

$200 \mathrm{rpm} / \mathrm{pH}$ control

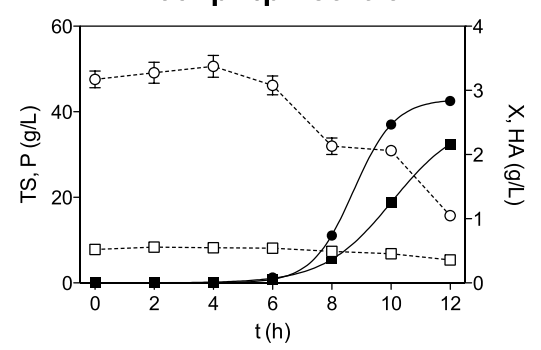

$500 \mathrm{rpm} / \mathrm{pH}$ control/1 vvm

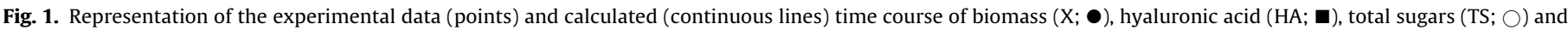

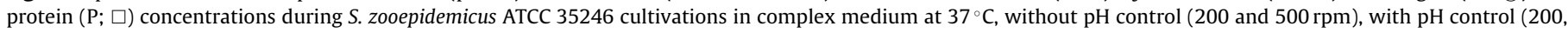
500 and $800 \mathrm{rpm}$ ) and with $1 \mathrm{vvm}$ aeration (500 and $800 \mathrm{rpm}$ ).

\section{Results and discussion}

\subsection{Effect of $p H$ control, agitation, and aeration on HA production}

The production of HA by S. zooepidemicus ATCC 35246 was studied in complex medium (CM) at $37^{\circ} \mathrm{C}$ under different agitation rates: 200,500 and $800 \mathrm{rpm}$, with ( $1 \mathrm{vvm}$ ) and without aeration. Also, the effect of pH control (at 6.7) was initially studied. The experimental data (biomass: $X$, and hyaluronic acid: $H$ ) were quantified and modelled using the logistic Eqs. (1) and (2), respectively. The agreement between predicted and experimental data was excellent (Table 2), with $\mathrm{R}^{2}$ - values higher than 0.973 . The $p$-values from Fisher's $F$-test also indicated the consistency of the models to describe the experimental data. In general, the kinetic parameters defined by Eqs. (1)-(3) were statistically significant for all the conditions assayed (Student's t-test, Table 2).

We studied the effect of $\mathrm{pH}$ control on HA production by carrying out four cultures at 200 and $500 \mathrm{rpm}$, with or without $\mathrm{pH}$ control (Fig. 1). Our results showed maximal HA concentrations achieved without $\mathrm{pH}$ control were almost negligible $\left(0.25 \mathrm{~g} \mathrm{~L}^{-1}\right)$, regardless of the agitation rate applied (Table 2 ). After $6 \mathrm{~h}$ of cultivation, the $\mathrm{pH}$ dropped to average values below 5 (data not shown), sugar uptake stopped, and biomass and hyaluronic acid productions reached the stationary phase (Fig. 1). The $\mathrm{pH}$ control had a remarkable effect on the maximum HA concentration, yield and volumetric production rates in batch cultures of $S$. zooepidemicus (Table 2). Cultivation at controlled $\mathrm{pH}$ led to a 7 to 8 -fold incre- ment in maximal HA productions compared to non-controlled $\mathrm{pH}$ cultures at identical agitation rates (Table 2). The highest maximal HA productions were $2.56 \mathrm{~g} \mathrm{~L}^{-1}$ and $2.19 \mathrm{~g} \mathrm{~L}^{-1}$ at $200 \mathrm{rpm}$ and $500 \mathrm{rpm}$, respectively. These results are in agreement with previous reports highlighting the importance of $\mathrm{pH}$ control on the parameters of HA production in batch cultures of S. zooepidemicus [28]. The maintenance of stable $\mathrm{pH}$ conditions such as those utilised in the present research (6.0-7.0) was reported to improve HA production $[10,28]$, by counteracting the lactic and acetic product formation that causes a strong inhibition of cell growth and polysaccharide synthesis [29].

The production of HA typically increases broth viscosity and thus agitation and oxygen mass transfer rates significantly influence HA production [8]. However, there is no agreement on whether high agitation enhances HA production or not. In this regard, some reports have shown a decrease in the polysaccharide production rates with increased mixing speed [30], while others have found opposite results [28,31]. Although agitation is needed to facilitate the transport of nutrients and to remove lactate in the environment of the cell [28], high agitation rates can be detrimental to HA production [31,32], and to the structure of the polymer [28]. Indeed, we observed increasing the agitation rate from $200 \mathrm{rpm}$ to $800 \mathrm{rpm}$ markedly reduced the maximum production of $\mathrm{HA}$ and the productivity while increasing the maximum biomass compared to lower agitation conditions (Table 2). The negative relationship between growth and specific HA productivity at increased stirring rates is due to HA production competing for limited resources with biomass 

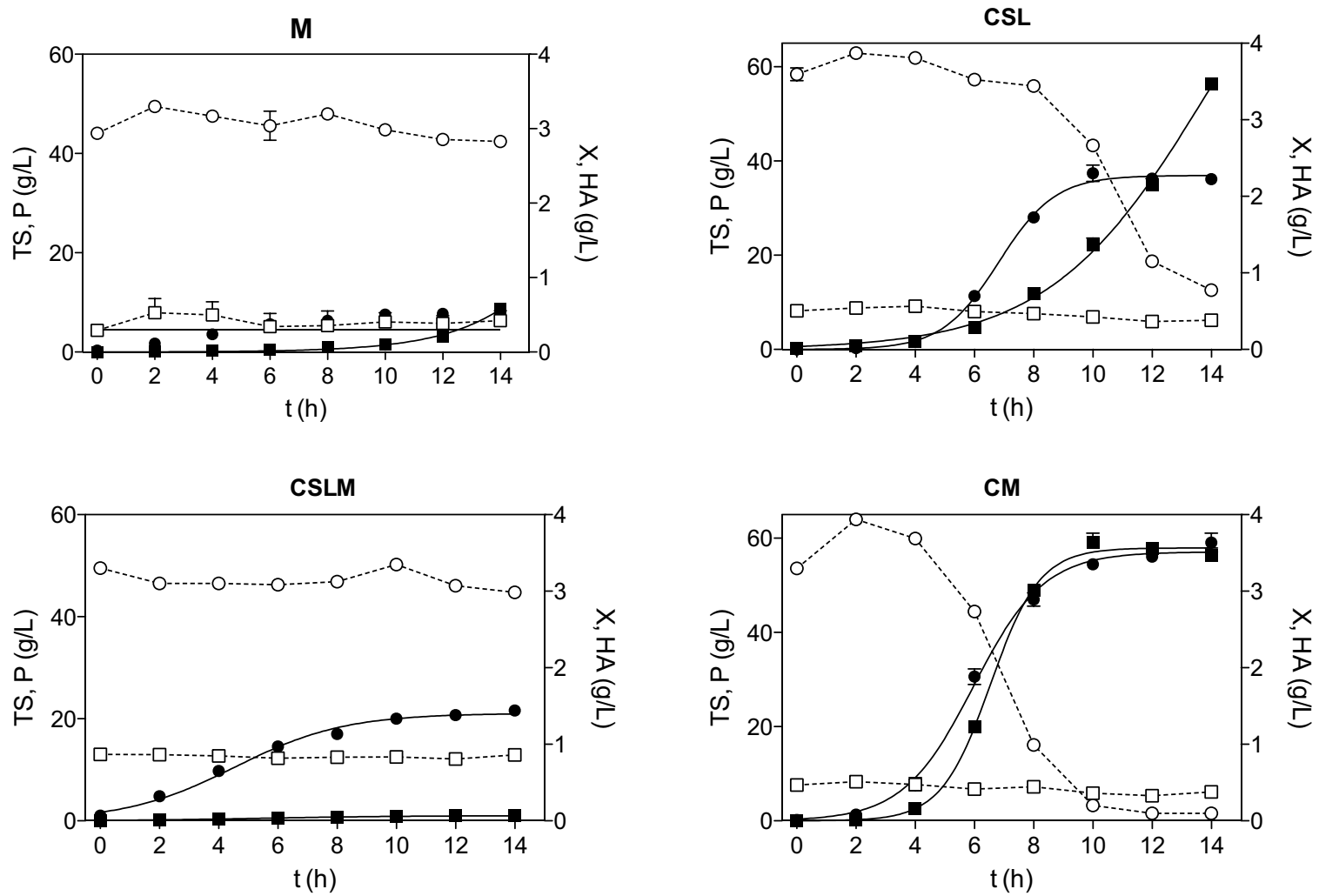

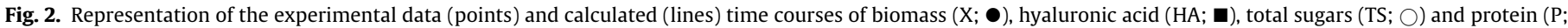

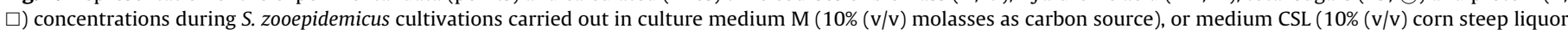
as nitrogen source), or medium $\operatorname{CSLM}(10 \%(\mathrm{v} / \mathrm{v})$ molasses $+10 \%(\mathrm{v} / \mathrm{v})$ corn steep liquor), or complex medium.

synthesis, as previously reported [33]. We also found higher agitation rates reduced the yield of HA on biomass $\left(Y_{H / X}\right.$; Table 2$)$, which dropped from $0.66 \mathrm{~g} \mathrm{~g}^{-1}$ at $200 \mathrm{rpm}$ to $0.51 \mathrm{~g} \mathrm{~g}^{-1}$ at $500 \mathrm{rpm}$ (Table 2). On the other hand, increasing the stirring speed significantly shortened $(>50 \%)$ the delay in HA production $\left(\lambda_{H}\right)$, being this time reduced from more than $7 \mathrm{~h}$ at $200 \mathrm{rpm}$ to only $3.37 \mathrm{~h}$ at $800 \mathrm{rpm}$. The inverse relationship between agitation rate and $\lambda_{H}$ agrees with previous findings [31,32], while contradicts others that report a delayed rate of HA synthesis under high shear stress conditions [34]. In addition to maximizing the production, culture conditions should speed up the process and reduce the production costs, and so only $500 \mathrm{rpm}$ and $800 \mathrm{rpm}$ conditions were considered for further experiments.

Aeration of $S$. zooepidemicus cultures was reported to enhance ATP production and increase acetyl-CoA accumulation, leading to higher HA titres [29]. Therefore, in principle, it is possible to shift the carbon flux towards HA synthesis in microbial cultures under aerobic conditions and so, an experiment followed where we studied the effect of aeration ( $1 \mathrm{vvm}$ ). Indeed, our results showed a 1.8 and 2.5- fold increment in maximal HA concentrations in aerated cultures at $500 \mathrm{rpm}$ and $800 \mathrm{rpm}$ compared to their non-aerated counterparts (Table 2). The yields of HA per biomass $\left(Y_{H / X}\right)$ were lower than 1.0 (Table 2), indicating glucose was utilised preferably for cell growth than HA synthesis, as previously reported [29]. However, cultivation conditions of $500 \mathrm{rpm}$ and $1 \mathrm{vvm}$ aeration provided a $Y_{H / X}$ value greater of $1.08 \mathrm{gg}^{-1}$, suggesting the carbon source goes mainly towards HA production rather than biomass synthesis (Table 2). Aeration at $1 \mathrm{vvm}$ doubled the value of $Y_{H / X}$ compared to the culture at $500 \mathrm{rpm}$ without aeration (Table 2) suggesting the carbon flux was diverted towards HA synthesis.
The average final molecular weight of HA in non-aerated cultures was $3.2 \times 10^{3} \mathrm{kDa}$ and $3.0 \times 10^{3} \mathrm{kDa}$ in aerated cultures. The slight reduced molecular weight observed might be related to the shear stress produced by high agitation rates and aeration of HA in accordance with previous results [28,34].

\subsection{HA production in low-cost formulated media}

The HA production in culture media formulated using agricultural by-products was tested using the conditions previously defined in $\mathrm{CM}$ medium providing the highest yields of HA per biomass: controlled $\mathrm{pH}$ (6.7), agitation of $500 \mathrm{rpm}$ and aeration of $1 \mathrm{vvm}$. We tested two culture media containing sugarcane molasses $(10 \% \mathrm{v} / \mathrm{v})$ as the carbon source with either tryptone $(\mathrm{M})$ or CSL (CSLM) as the nitrogen source, and a third culture medium containing $50 \mathrm{~g} \mathrm{~L}^{-1}$ glucose and $10 \%(\mathrm{v} / \mathrm{v}) \mathrm{CSL}(\mathrm{CSL})$. We compared these results with a synthetic medium (CM) containing $50 \mathrm{~g} \mathrm{~L}^{-1}$ glucose and tryptone. All media contained yeast extract and total sugars at a concentration of $50 \mathrm{~g} \mathrm{~L}^{-1}$ (Table 1).

Both glucose-containing media either with $\operatorname{CSL}\left(3.48 \mathrm{~g} \mathrm{~L}^{-1}\right)$ or tryptone $\left(3.60 \mathrm{~g} \mathrm{~L}^{-1}\right)$ as the main nitrogen source produced similar final HA concentrations (Fig. 2), despite the first showed a lower productivity and the production was delayed (Table 3). Contrarily, molasses-formulated media ( $\mathrm{M}$ and CSLM) produced the lowest biomass and HA synthesis, achieving almost negligible HA concentrations (Fig. 2). According to HPLC analysis, sucrose was the primary sugar (98\%) in sugarcane molasses. The uptake of this disaccharide was reported in S. zooepidemicus $[22,29,33]$ up to an initial content of $60 \mathrm{~g} \mathrm{~L}^{-1}$, although with a strong inhibition on cell growth at high concentrations $\left(70 \mathrm{~g} \mathrm{~L}^{-1}\right)$ [29]. Jagganath and Ramachandran reported replacing glucose with sucrose increased 
Table 2

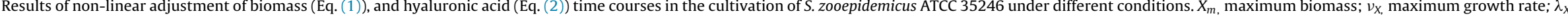

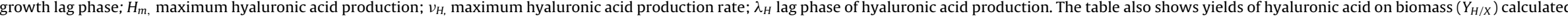
using Eq. (3). The determination coefficients $\left(\mathrm{R}^{2}\right)$ and $p$-values from Fisher's F-test for the mathematical are shown. NS, not significant.

\begin{tabular}{|c|c|c|c|c|c|c|c|c|c|c|c|c|c|}
\hline \multirow[t]{2}{*}{ Cultivation conditions } & \multicolumn{5}{|l|}{ Biomass } & \multicolumn{5}{|c|}{ Hyaluronic acid production } & \multicolumn{3}{|l|}{ Yield } \\
\hline & $\overline{X_{m}\left(\mathrm{~g} \mathrm{~L}^{-1}\right)}$ & $v_{X}\left(g L^{-1} h^{-1}\right)$ & $\lambda_{X}(h)$ & $R^{2}$ & $\overline{p \text {-value }}$ & $\overline{H_{m}\left(\mathrm{~g} \mathrm{~L}^{-1}\right)}$ & $v_{H}\left(g L^{-1} h^{-1}\right)$ & $\lambda_{H}(\mathrm{~h})$ & $R^{2}$ & $\overline{p \text {-value }}$ & $\overline{Y_{H / X}\left(g g^{-1}\right)}$ & $R^{2}$ & $\overline{p \text {-value }}$ \\
\hline $200 \mathrm{rpm}$ & $1.03 \pm 0.05$ & $0.22 \pm 0.04$ & $2.49 \pm 0.51$ & 0.991 & $<0.001$ & $0.25 \pm<0.01$ & $0.12 \pm 0.02$ & $2.00 \pm 0.23$ & 0.996 & $<0.001$ & $0.23 \pm 0.17$ & 0.949 & $<0.001$ \\
\hline $500 \mathrm{rpm}$ & $1.08 \pm 0.06$ & $0.19 \pm 0.03$ & $2.25 \pm 0.50$ & 0.992 & $<0.001$ & $0.25 \pm<0.01$ & $0.13 \pm<0.01$ & $2.06 \pm 0.09$ & 0.999 & $<0.001$ & $0.23 \pm 0.13$ & 0.778 & 0.002 \\
\hline $200 \mathrm{rpm} / \mathrm{pH}$ control $/ 0 \mathrm{vvm}$ & $2.87 \pm 0.03$ & $1.02 \pm 0.03$ & $7.33 \pm 0.05$ & 0.999 & $<0.001$ & $2.56 \pm 0.06$ & $0.56 \pm 0.01$ & $7.76 \pm 0.06$ & 0.999 & $<0.001$ & $0.66 \pm 0.13$ & 0.776 & 0.002 \\
\hline $500 \mathrm{rpm} / \mathrm{pH}$ control $/ 0 \mathrm{vvm}$ & $3.39 \pm 0.06$ & $0.74 \pm 0.04$ & $3.88 \pm 0.15$ & 0.999 & $<0.001$ & $2.19 \pm 0.03$ & $0.53 \pm 0.03$ & $4.10 \pm 0.14$ & 0.999 & $<0.001$ & $0.51 \pm 0.36$ & 0.658 & 0.005 \\
\hline $800 \mathrm{rpm} / \mathrm{pH}$ control $/ 0 \mathrm{vvm}$ & $2.748 \pm 0.09$ & $0.78 \pm 0.12$ & $3.59 \pm 0.33$ & 0.996 & $<0.001$ & $1.30 \pm 0.15$ & $0.22 \pm 0.07$ & $3.37 \pm 1.00$ & 0.973 & $<0.001$ & 0.36 (NS) & 0.964 & $<0.001$ \\
\hline $500 \mathrm{rpm} / \mathrm{pH}$ control $/ 1 \mathrm{vvm}$ & $2.30 \pm 0.03$ & $0.71 \pm 0.05$ & $3.59 \pm 0.13$ & 0.999 & $<0.001$ & $3.95 \pm 0.19$ & $0.74 \pm 0.09$ & $4.63 \pm 0.36$ & 0.996 & $<0.001$ & $1.08 \pm 0.44$ & 0.881 & $<0.001$ \\
\hline $800 \mathrm{rpm} / \mathrm{pH}$ control $/ 1 \mathrm{vvm}$ & $3.65 \pm 0.06$ & $0.72 \pm 0.06$ & $5.03 \pm 0.17$ & 0.999 & $<0.001$ & $3.29 \pm 0.14$ & $0.72 \pm 0.09$ & $5.71 \pm 0.30$ & 0.997 & $<0.001$ & $0.84 \pm 0.16$ & 0.968 & $<0.001$ \\
\hline
\end{tabular}

Table 3

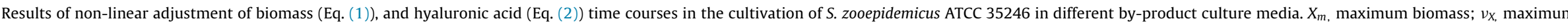

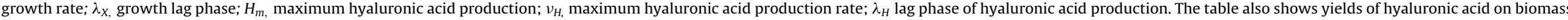
calculated using Eq. (3). The determination coefficients $\left(\mathrm{R}^{2}\right)$ and $p$-values from Fisher's F-test for the mathematical are shown. NS, not significant.

\begin{tabular}{|c|c|c|c|c|c|c|c|c|c|c|c|c|c|}
\hline \multirow[t]{2}{*}{ Culture medium } & \multicolumn{5}{|l|}{ Biomass } & \multicolumn{5}{|c|}{ Hyaluronic acid production } & \multicolumn{3}{|l|}{ Yield } \\
\hline & $X_{m}\left(\mathrm{~g} \mathrm{~L}^{-1}\right)$ & $v_{X}\left(g L^{-1} h^{-1}\right)$ & $\lambda_{X}(h)$ & $R^{2}$ & $\overline{p \text {-value }}$ & $H_{m}\left(\mathrm{~g} \mathrm{~L}^{-1}\right)$ & $v_{H}\left(g L^{-1} h^{-1}\right)$ & $\lambda_{H}(\mathrm{~h})$ & $R^{2}$ & $\overline{p \text {-value }}$ & $Y_{H / X}\left(g g^{-1}\right)$ & $R^{2}$ & $p$-value \\
\hline M & $0.52 \pm 0.08$ & $0.07 \pm 0.04$ & 0.68 (NS) & 0.973 & 0.003 & $40.9(\mathrm{NS}))$ & $4.64(\mathrm{NS})$ & $19.0(\mathrm{NS})$ & 0.974 & 0.002 & $0.80 \pm 0.71$ & 0.765 & 0.002 \\
\hline CSL & $2.27 \pm 0.06$ & $0.59 \pm 0.08$ & $4.90 \pm 0.29$ & 0.996 & $<0.001$ & $6.82 \pm 2.88$ & $0.63 \pm 0.16$ & $8.65 \pm 1.25$ & 0.995 & $<0.001$ & $1.01 \pm 0.60$ & 0.884 & 0.002 \\
\hline CSLM & $1.40 \pm 0.08$ & $0.19 \pm 0.03$ & $0.84(\mathrm{NS})$ & 0.985 & $<0.001$ & $0.07 \pm 0.01$ & $0.007 \pm<0.01$ & 0.62 (NS) & 0.967 & 0.005 & $0.05 \pm 0.01$ & 0.915 & $<0.001$ \\
\hline $\mathrm{CM}$ & $3.51 \pm 0.11$ & $0.74 \pm 0.10$ & $3.59 \pm 0.37$ & 0.996 & $<0.001$ & $3.56 \pm 0.08$ & $1.07 \pm 0.14$ & $4.88 \pm 0.23$ & 0.997 & $<0.001$ & $1.02 \pm 0.13$ & 0.987 & $<0.001$ \\
\hline
\end{tabular}


the HA productivity and molecular weight, together with the specific HA synthesis rate [33]. Unlike these reports and in accordance with the results presented in this study, the use of sugarcane molasses has shown low productions of HA $\left(0.376 \pm 0.020 \mathrm{~g} \mathrm{~L}^{-1}\right)$, compared to commercial sucrose $\left(0.488 \pm 0.002 \mathrm{~g} \mathrm{~L}^{-1}\right)$ and glucose $\left(0.429 \pm 0.028 \mathrm{~g} \mathrm{~L}^{-1}\right)[22]$. These findings suggest the inhibition observed in S. zooepidemicus growth in molasses-containing media must be due to other components of this by-product, such as lactic acid [29] and phenolic compounds [35] that were reported as inhibitory against Streptococci. A further pre-treatment of molasses, i.e. the use of acid hydrolysis and/or an activated carbon resin to reduce the content of inhibitory compounds and improve the HA titres.

The use of CSL as alternative nitrogen source for HA production has been scarcely studied to date, and has shown mixed results. For instance, Pires et al. [21] found nearly identical maximal HA production in culture media $\left(45 \mathrm{~g} \mathrm{~L}^{-1}\right.$ of glucose and $57 \mathrm{~g} \mathrm{~L}^{-1}$ yeast extract) with $\left(0.84 \mathrm{~g} \mathrm{~L}^{-1}\right)$ and without $\left(0.86 \mathrm{~g} \mathrm{~L}^{-1}\right) \mathrm{CSL}(10 \% \mathrm{v} / \mathrm{v})$ supplementation. These authors reported however, a 2-fold increment in the yield of HA on glucose when using the by-product. On the other hand, Pan et al. [22] did not find any HA production in culture media containing CSL and yeast extract $\left(30 \mathrm{~g} \mathrm{~L}^{-1}\right)$ as the nitrogen sources, using either glucose or sucrose $\left(30 \mathrm{~g} \mathrm{~L}^{-1}\right)$ as carbon sources. The final HA concentration reported in the present study was higher $\left(3.60 \mathrm{gL}^{-1}\right)$ than any other reported before in culture media containing CSL. These differences must be related to variations in experimental conditions, such as different S. zooepidemicus strains, ATCC $39920[21,22]$ or ATCC 35246, changes in the composition of the culture media, and cultivation mode. The latter may be primarily responsible for the differences in polysaccharide productions, i.e. S. zooepidemicus cultivation in bioreactor instead of Erlenmeyer flasks [21,22]. This type of culture does not allow automatic control of $\mathrm{pH}$ and a high concentration of lactic acid accumulates in the cell environment, lowering the $\mathrm{pH}$ and inhibiting cell growth and HA synthesis [29].

The yields of HA per biomass in CSL and CM media were very similar (Table 3 ), suggesting CSL could be a low-cost alternative to expensive commercial peptones such as tryptone $(\sim 300$ $€ \mathrm{~kg}^{-1}$ ). Previous findings have shown the use of different substrates changes the glycolytic end products [36], and regulate the molecular weight of HA [33]. The average molecular weight of HA produced in CSL medium was $3.8 \times 10^{3} \mathrm{kDa}$, which is higher than in CM medium $\left(3.0 \times 10^{3} \mathrm{kDa}\right)$ using the same culture conditions. Cheese whey formulated medium [18] produced HA with the average molecular weight $\left(3.8 \times 10^{3} \mathrm{kDa}\right)$ to CSL medium. These differences might be related to the regulation of the molecular weight of HA caused by the use different nutritive sources [33].

The final production of HA in CSL medium was higher than the concentrations reported in culture media containing cheese whey [16] or marine peptones from fishing by-products (1.51-2.41 $\left.\mathrm{g} \mathrm{L}^{-1}\right)$ as the nitrogen sources [15-17]. Both CSL and whey protein enhanced the conversion of the carbon source towards HA production instead of biomass synthesis, leading to yields of HA on biomass $\left(Y_{H / X}\right)$ higher than 1 while marine peptones produced more biomass than polysaccharide $\left(Y_{H / X}=0.4-0.7\right)$. Remarkably, the use of CSL as the nitrogen source in $S$. zooepidemicus cultures delayed HA synthesis ( $8.65 \mathrm{~h}$ ) compared to fish and cheese byproduct formulated media $(3.30-7.66 \mathrm{~h})$, which would be a limiting factor for the use of this alternative nitrogen source for the industrial production of HA. To overcome this issue, further optimization of culture medium composition and the use of alternative cultivation strategies must be approached. For instance, fed-batch cultures were reported to increase HA productions in different alternative culture media $[15,17,29]$. Also the use of a two-step culture model consisting of an initial exponential fed-batch culture phase maintaining low sugar concentrations $(0-8 \mathrm{~h})$ followed by batch fermentation ( $8-20 \mathrm{~h})$, increased HA production by $36 \%$ compared to $S$. zooepidemicus batch cultivation $[29,37]$.

\section{Conclusions}

In this study, low-cost culture media were formulated using two agro-industrial by-products (corn steep liquor and/or molasses) for HA production by $S$. zooepidemicus. Molasses-containing media with tryptone or CSL as nitrogen source produced a strong inhibition in S. zooepidemicus growth under optimized culture conditions. The amount of HA produced in glucose and CSL-containing medium was $3.48 \mathrm{~g} \mathrm{~L}^{-1}$, comparable to that of complex medium $\left(3.60 \mathrm{~g} \mathrm{~L}^{-1}\right)$, and higher than those reported using animal-sourced agrifood wastes $\left(1.51-2.41 \mathrm{~g} \mathrm{~L}^{-1}\right)$. The HA production was delayed in CSL formulated medium and so, further optimization of the nutrient composition, and/or alternative culture strategies must be explored.

\section{Acknowledgements}

Isabel Rodríguez was funded by a postdoctoral contract from the Xunta de Galicia, Spain (Plan I2C, 2012). This research was financially supported by projects: MAT2010-21509-C03-01 (Ministerio de Economía y Competitividad, Spain) and FP7 Project BiValBi. Biotechnologies to Valorise the regional food Biodiversity in Latin America (PIRSES-GA-2013-611493). The authors want to thank by RAR: Refinarias de Açuícar Reunidas, S.A. (Portugal), and COPAM: Companhia Portuguesa de Amidos, S.A. (Portugal) for providing the molasses and CSL utilised to conduct this research. We also wish to thank to Ana Durán and Margarita Nogueira (IIM-CSIC) for their excellent technical assistance.

\section{References}

[1] B. Weissmann, K. Meyer, The structure of hyalobiuronic acid and of hyaluronic acid from umbilical cord, J. Am. Chem. Soc. 76 (1954) 1753-1757.

[2] M.K. Cowman, H.-G. Lee, K.L. Schwertfeger, J.B. Mccarthy, E.A. Turley, The content and size of hyaluronan in biological fluids and tissues, Front. Immunol. 6 (2015).

[3] U. Anderegg, J. Simon, M. Averbeck, More than just a filler- the role of hyaluronan for skin homeostasis, Exp. Dermatol. 23 (2014) 295-303.

[4] B. Chen, R. Miller, P. Dhal, Hyaluronic acid-based drug conjugates: state-of-the-art and perspectives, J. Biomed. Nanotechnol. 10 (2014) 4-16.

[5] D. Cimini, M.D. de Rosa, C. Schiraldi, Production of glucuronic acid-based polysaccharides by microbial fermentation for biomedical applications, Biotechnol. J. 7 (2012) 237-250.

[6] A. Shiedlin, R. Bigelow, W. Christopher, S. Arbabi, L. Yang, R. Maier, et al., Evaluation of hyaluronan from different sources: Streptococcus zooepidemicus, rooster comb, bovine vitreous, and human umbilical cord, Biomacromolecules 5 (2004) 2122-2127.

[7] M.A. Murado, M.I. Montemayor, M.L. Cabo, J.A. Vázquez, M.P. González, Optimization of extraction and purification process of hyaluronic acid from fish eyeball, Food Bioprod. Proc. 90 (2012) 491-498.

[8] L. Liu, Y. Liu, J. Li, G. Du, J. Chen, Microbial production of hyaluronic acid: current state, challenges, and perspectives, Microb. Cell Fact. 10 (2011) 99.

[9] T. Yamada, T. Kawasaki, Microbial synthesis of hyaluronan and chitin: new approaches, J. Biosci. Bioeng. 99 (2005) 521-528.

[10] D.C. Armstrong, M.J. Cooney, M.R. Johns, Growth and amino acid requirements of hyaluronic-acid producing Streptococcus zooepidemicus, Appl. Microbiol. Biotechnol. 47 (1997) 309-312.

[11] K. Hofvendahl, B. Hahn-Hägerdal, Factors affecting the fermentative lactic acid production from renewable resources, Enzyme Microb. Technol. 26 (2000) 87-107.

[12] L.R. Rodrigues, J.A. Teixeira, R. Oliveira, Low-cost fermentative medium for biosurfactant production by probiotic bacteria, Biochem. Eng. J. 32 (2006) $135-142$.

[13] E. Gudiña, A. Rodrigues, E. Alves, M. Domingues, J. Teixeira, L. Rodrigues, Bioconversion of agro-industrial by-products in rhamnolipids toward applications in enhanced oil recovery and bioremediation, Bioresour. Technol. 177 (2015) 87-93.

[14] J. Vázquez, I. Rodríguez-Amado, M. Montemayor, J. Fraguas, P. González, M. Murado, Chondroitin sulphate, hyaluronic acid and chitin/chitosan production using marine waste sources: characteristics, applications and eco-friendly processes: a review, Mar. Drugs 11 (2013) 747-774. 
[15] J.A. Vázquez, M.I. Montemayor, J. Fraguas, M.A. Murado, High production of hyaluronic and lactic acids by Streptococcus zooepidemicus in fed-batch culture using commercial and marine peptones from fishing by-products, Biochem. Eng. J. 44 (2009) 125-130.

[16] J.A. Vázquez, M.I. Montemayor, J. Fraguas, M.A. Murado, Hyaluronic acid production by Streptococcus zooepidemicus in marine by-products media from mussel processing wastewaters and tuna peptone viscera, Microb. Cell Fact 9 (2010).

[17] J.A. Vázquez, L. Pastrana, C. Piñeiro, J.A. Teixeira, R.I. Pérez-Martín, I.R. Amado, Production of hyaluronic acid by Streptococcus zooepidemicus on protein substrates obtained from Scyliorhinus canicula discards, Mar. Drugs 13 (2015) 6537-6549.

[18] I.R. Amado, J.A. Vázquez, L. Pastrana, J.A. Teixeira, Cheese whey: a cost-effective alternative for hyaluronic acid production by Streptococcus zooepidemicus, Food Chem. (2015), in press.

[19] L.J. Benedini, M.H.A. Santana, Effects of soy peptone on the inoculum preparation of Streptococcus zooepidemicus for production of hyaluronic acid, Bioresour. Technol. 130 (2013) 798-800.

[20] A.C. De Macedo, M. Santana, Hyaluronic acid depolymerisation by ascorbate-redox effects on solid state cultivation of Streptococcus zooepidemicus in cashew apple fruit bagasse, World J. Microbiol. Biotechnol. 28 (2012) 2213-2219.

[21] A. Pires, A. Macedo, S. Eguchi, M. Santana, Microbial production of hyaluronic acid from agricultural resource derivatives, Bioresour. Technol. 101 (2010) 6506-6509.

[22] N.C. Pan, J.A. Vignoli, C. Baldo, H.C.B. Pereira, R.S.D.S. Ferreira Da Silva, M.A.P.C. Celligoi, Agroindustrial by-products for the production of hyluronic acid by Streptococcus zooepidemicus ATCC 39920, Int. J. Sci. Technol. Res. 4 (2015) 114-118.

[23] M. Dubois, K. Gilles, J. Hamilton, P. Rebers, F. Smith, Colorimetric method for determination of sugars and related substances, Anal. Chem. 28 (1956) 350-356.

[24] O.H. Lowry, N.J. Rosebrough, A.L. Farr, R.J. Randall, Protein measurement with the folin phenol reagent, J. Biol. Chem. 193 (1951) 265-275.

[25] N. Blumenkrantz, G. Asboe-Hansen, New method for quantitative determination of uronic acids, Anal. Biochem. 54 (1973) 484-489.

[26] M.A. Murado, J.A. Vázquez, M.I. Montemayor, M.L. Cabo, P. González, et al., Two mathematical models for the correction of carbohydrate and protein interference in the determination of uronic acids by the m-hydroxydiphenyl method, Biotechnol. Appl. Biochem. 216 (2005) 209-216.

[27] M. Don, N. Shoparwe, Kinetics of hyaluronic acid production by Streptococcus zooepidemicus considering the effect of glucose, Biochem. Eng J. 49 (2010) 95-103.

[28] M.R. Johns, L.-T. Goh, A. Oeggerli, Effect of pH, agitation and aeration on hyaluronic acid production by Streptococcus zooepidemicus, Biotechnol. Lett. 16 (1994) 507-512.

[29] L. Liu, G. Du, J. Chen, M. Wang, J. Sun, Enhanced hyaluronic acid production by a two-stage culture strategy based on the modelling of batch and fed-batch cultivation of Streptococcus zooepidemicus, Bioresour. Technol. 99 (2008) 8532-8536.

[30] J.H. Kim, S.J. Yoo, D.K. Oh, Y.G. Kweon, D.W. Park, C.H. Lee, et al., Selection of a Streptococcus equi mutant and optimization of culture conditions for the production of high molecular weight hyaluronic acid, Enz. Microb. Technol. 19 (2007) 440-445.

[31] S. Hasegawa, M. Nagatsuru, M. Shibutani, Productivity of concentrated hyaluronic acid using maxblend fermentor, J. Biosci. Bioeng. 88 (1999) 68-71.

[32] W.-C. Huang, S.-J. Chen, T.-L. Chen, The role of dissolved oxygen and function of agitation in hyaluronic acid fermentation, Biochem. Eng. J. 32 (2006) 239-243.

[33] S. Jagannath, K.B. Ramachandran, Influence of competing metabolic processes on the molecular weight of hyaluronic acid synthesized by Streptococcus zooepidemicus, Biochem. Eng. J. 48 (2010) 148-158.

[34] X.J. Duan, L. Yang, X. Zhang, W.S. Tan, Effect of oxygen and shear stress on molecular weight of hyaluronic acid produced by Streptococcus zooepidemicus, J. Microbiol. Biotechnol. 18 (2008) 718-724.

[35] K. Takara, K. Ushijima, K. Wada, H. Iwasaki, M. Yamashita, Phenolic compounds from sugarcane molasses possessing antibacterial activity against cariogenic bacteria, J. Oleo Sci 56 (2007) 611-614.

[36] T.D. Thomas, K.W. Turner, V.L. Crow, Galactose fermentation by Streptococcus lactis and Streptococcus cremoris: Pathways, products, and regulation, J. Bacteriol. 144 (1980) 672-682.

[37] L. Liu, G. Du, J. Chen, M. Wang, J. Sun, Influence of culture modes on the microbial production of hyaluronic acid by Streptococcus zooepidemicus, Biotechnol. Bioproc. Eng. 13 (2008) 269-273. 